\title{
The Chemogenetic Receptor Ligand Clozapine N-Oxide Induces in vivo Neuroreceptor Occupancy and Reduces Striatal Glutamate Levels
}

\author{
Simone Bærentzen ${ }^{1,2}$, Agata Casado-Sainz ${ }^{1}$, Denise Lange ${ }^{1,3}$, Vladimir Shalgunov ${ }^{4}$, \\ Isabel Martinez Tejada', Mengfei Xiong ${ }^{1,4}$, Elina T. L'Estrade ${ }^{1,4,5}$, Fraser G. Edgar', \\ Hedok Lee ${ }^{6}$, Matthias M. Herth ${ }^{1,4,7}$ and Mikael Palner ${ }^{1,2 *}$ \\ ${ }^{1}$ Neurobiology Research Unit, Copenhagen University Hospital, Copenhagen, Denmark, ${ }^{2}$ Center for Translational \\ Neuromedicine, University of Copenhagen, Copenhagen, Denmark, ${ }^{3}$ Institute of Aerospace Medicine, German Aerospace \\ Center (DLR), Cologne, Germany, ${ }^{4}$ Department of Drug Design and Pharmacology, University of Copenhagen, Copenhagen, \\ Denmark, ${ }^{5}$ Radiation Physics, Nuclear Medicine Physics Unit, Skånes University Hospital, Lund, Sweden, ${ }^{6}$ Department \\ of Anesthesiology and Pediatric Anesthesiology, Yale University, New Haven, CT, United States, ${ }^{7}$ Department of Clinical \\ Physiology, Nuclear Medicine and PET, Copenhagen University Hospital, Copenhagen, Denmark
}

OPEN ACCESS

Edited by:

Pascal Bonaventure, Janssen Research and Development, United States

Reviewed by:

Clinton Canal,

Mercer University, United States Rodrigo España,

Drexel University, United States

*Correspondence:

Mikael Palner

mikael.palner@nru.dk

Specialty section This article was submitted to Neuropharmacology, a section of the journal Frontiers in Neuroscience

Received: 06 July 2018 Accepted: 15 February 2019

Published: 03 April 2019

Citation:

Bærentzen S, Casado-Sainz A Lange D, Shalgunov V, Tejada IM, Xiong M, L'Estrade ET, Edgar FG, Lee H, Herth MM and Palner M (2019) The Chemogenetic Receptor Ligand Clozapine N-Oxide Induces in vivo Neuroreceptor Occupancy and Reduces Striatal G/utamate Levels. Front. Neurosci. 13:187. doi: 10.3389/fnins.2019.00187
Chemogenetic studies with the ligand clozapine $\mathrm{N}$-oxide (CNO) are predicated upon the assumption that $\mathrm{CNO}$ is devoid of actions at natural neuroreceptors. However, recent evidence shows that $\mathrm{CNO}$ may be converted back to clozapine (CLZ) in vivo, which could yield plasma concentrations that may be sufficient to occupy inter alia dopamine $\mathrm{D}_{2 / 3}$ and serotonin $5 \mathrm{HT}_{2 A}$ receptors in living brain. To test this phenomenon, we measured striatal dopamine $D_{2 / 3}$ receptor occupancy with $\left[{ }^{18} \mathrm{~F}\right]$ fallypride PET and serotonin $5 \mathrm{HT}_{2 A}$ occupancy ex vivo using $\left[{ }^{18} \mathrm{~F}\right] \mathrm{MH} . \mathrm{MZ}$. We found a CNO dosedependent effect on the availability of both neuroreceptor sites. In parallel MR spectroscopy experiments, we found that $\mathrm{CNO}$ reduced creatine + phosphcreatine $(\mathrm{Cr}+\mathrm{PCr})$ and increased $\mathrm{N}$-acetylaspartate $+\mathrm{N}$-acetylaspartylglutamate (NAA+NAAG) signals in the prefrontal cortex, and also reduced the glutamate signal in dorsal striatum, with peak effect at $2 \mathrm{mg} / \mathrm{kg}$. Thus, our findings suggest that conversion of $\mathrm{CNO}$ to $\mathrm{CL} Z$ in living rats imparts significant occupancy at endogenous neuroreceptors and significant changes to neurometabolite levels.

Keywords: DREADD, CNO, clozapine, dopamine receptors, serotonin receptors, glutamate

\section{INTRODUCTION}

Designer Receptors Exclusively Activated by Designer Drugs (DREADDs) are bioengineered from the muscarinic $\mathrm{G}$ protein-coupled receptor and have no natural ligand, but possess high agonistic affinity for the exogenous ligand clozapine $\mathrm{N}$-oxide (CNO) (Armbruster et al., 2007). These receptors can be expressed with coupling to the $\mathrm{Gq}, \mathrm{Gi}$, and $\mathrm{Gs}$ signal transduction pathways, thus affording a powerful tool to study pathway-specific G-protein function of brain and peripheral nerves. CNO is a major metabolite of clozapine (CLZ) (Baldessarini et al., 1993), which is a widely used atypical antipsychotic medication with binding to a broad range of neuroreceptors, namely dopamine $\mathrm{D}_{4}, \mathrm{D}_{2}, \mathrm{D}_{3}$, serotonin 5- $\mathrm{HT}_{2 A}, 5-\mathrm{HT}_{2} \mathrm{C}$, muscarinic $\mathrm{M}_{1}, \mathrm{M}_{2}, \mathrm{M}_{3}, \mathrm{M}_{4}$, adrenergic $\alpha_{1}$ and $\alpha_{2}$, as well as histamine $\mathrm{H}_{1}$ receptors. Furthermore, CLZ is also a high affinity agonist ligand for 
the DREADDs (Schotte et al., 1993; Bymaster et al., 1996; Zhang and Bymaster, 1999; Chen et al., 2015). While CNO is considered devoid of any specific binding other than to DREADD, recent studies suggest that $\mathrm{CNO}$ can convert back to CLZ in living rats (MacLaren et al., 2016) and dogs (Meier, 1975). Although CLZ was not detectable in plasma after a low administered dose of CNO (1 mg/kg) (Jann et al., 1993), a high dose of CNO $(20 \mathrm{mg} / \mathrm{kg})$ evoked measurable formation of plasma CLZ (Lin et al., 1996). CLZ has high uptake in rat brain, with a brain-to-plasma ratio of 24:1 (Baldessarini et al., 1993), predicting that much of the CLZ produced from CNO metabolism will accumulate in brain. In contrast, untransformed CNO has low permeability to the rat blood brain barrier (Gomez et al., 2017) and is therefore mainly confined to the plasma compartment of CLZ-treated rats (Baldessarini et al., 1993). Given this background, it has been suggested that the action of CNO on DREADDs in the brain is obtained solely via its metabolite CLZ (Gomez et al., 2017).

If CLZ is indeed the in vivo DREADD activator, it becomes imperative to confirm that a usual dose of CNO (or CLZ) does not interfere with other binding sites. CLZ is known to have in vivo occupancy at brain dopamine $\mathrm{D}_{2 / 3}$ receptors (Mukherjee et al., 2001; Olsen et al., 2008) as well as serotonin $5-\mathrm{HT}_{2 A}$ receptors in direct proportion to plasma concentrations (Knauer et al., 2008). Furthermore, CLZ treatment has been reported to alter in vivo levels of glutamate (Glu), N-acetylaspartate (NAA) and $N$-acetylaspartylglutamate (NAAG), albeit without direct relationship to the plasma CLZ concentration (Lidsky et al., 1993; Yamamoto and Cooperman, 1994; Arun et al., 2008; Krivoy et al., 2017). Therefore, brain concentrations of these neurochemcials can serve as surrogate indicators of central actions of the CNO metabolite.

To test our hypothesis that metabolism of CNO to CLZ in vivo induces blockade of $\mathrm{D}_{2 / 3}$ and $5-\mathrm{HT}_{2 A}$ receptors, we examined the CNO-induced in vivo receptor occupancy in conjunction with two available PET tracers, the dopamine $\mathrm{D}_{2 / 3}$ radioligand $\left[{ }^{18} \mathrm{~F}\right]$ fallypride and the serotonin $5-\mathrm{HT}_{2 A}$ receptor radioligand $\left[{ }^{18} \mathrm{~F}\right] \mathrm{MH} . \mathrm{MZ}$. We chose to inject CNO $20 \mathrm{~min}$ before experimental procedures to ensure translatability with previously published animal studies (Agulhon et al., 2013; Urban et al., 2015; Baslow et al., 2016). Furthermore, to test for effects of the treatment on neurometabolites, we also examined neurochemical changes in the prefrontal cortex and striatum using Magnetic Resonance Spectroscopy (MRS). These experiments provide relevant information about dose-dependent effects of $\mathrm{CNO}$ at neuroreceptors in Long-Evans rats and may call for reinterpretation of some DREADD experiments published prior to the identification of CLZ as the in vivo activator after $\mathrm{CNO}$ administration.

\section{MATERIALS AND METHODS}

\section{Animals}

Long-Evans rats were bred at the Department of Experimental Medicine Biocenter (AEM, University of Copenhagen). The rats were housed in groups of 2-4 animals per cage in a climatecontrolled rodent facility with $12 \mathrm{~h} / 12 \mathrm{~h}$ light/dark cycle. The rats were fed ad libitum and had free access to water. Female rats were used for the PET and MRS scans, while both male and female rats where used in the ex vivo experiment. All procedures were conducted in accordance with the FELASA guidelines for animal research and with approval from The Danish Animal Experiments Inspectorate (license number: 201615-0201-01031) as well as the Department of Experimental Medicine, University of Copenhagen.

\section{Chemicals}

Radiochemicals were produced in house as described below. CNO was provided by BioNordika Denmark and all other chemicals were from standard vendors.

\section{Radiosyntheses of $\left[{ }^{18} \mathrm{~F}\right]$ Fallypride}

$\left[{ }^{18} \mathrm{~F}\right]$ Fallypride was synthesized as previously described (Piel et al., 2014). In short, the tosyl-fallypride precursor $(0.2 \mathrm{mg})$ in $1 \mathrm{~mL}$ dimethylsulfoxide (DMSO) was added to the dried $\left[{ }^{18} \mathrm{~F}\right] \mathrm{KF}-\mathrm{K}_{222}$ complex via automated injection and was heated to $150^{\circ} \mathrm{C}$ for $20 \mathrm{~min}$. The product was then purified using a semipreparative HPLC method (Luna, $10 \mu \mathrm{m}$, C-18 column; 20\% ethanol in $0.1 \%$ phosphoric acid in water-retention time $10 \mathrm{~min}$ ). Purity of the isolated product was confirmed by analytical HPLC (Kinetic, C-18 with pre-column; 25\% acetonitrile in $0.1 \%$ phosphoric acid in water; $1.5 \mathrm{~mL} / \mathrm{min}$ - retention time $1.12 \mathrm{~min})$. The radiochemical purity of $\left[{ }^{18} \mathrm{~F}\right]$ fallypride was $99 \%$ and molar activity was $68 \mathrm{GBq} / \mu \mathrm{mol}$. The resulting ethanol tracer solutions were diluted to the necessary volume in $0.1 \mathrm{M}$ sterile phosphate buffer.

\section{Radiosyntheses of $\left[{ }^{18} \mathrm{~F}\right] \mathrm{MH} . \mathrm{MZ}$}

$\left[{ }^{18} \mathrm{~F}\right] \mathrm{MH} . \mathrm{MZ}$ was synthesized as previously described (Herth et al., 2008). In brief, MDL 105,725 was alkylated with 2$\left[{ }^{18} \mathrm{~F}\right]$ fluoroethyl tosylate $\left(\left[{ }^{18} \mathrm{~F}\right] \mathrm{FEtTos}\right)$ using an automated synthesis module. Identity of $\left[{ }^{18} \mathrm{~F}\right] \mathrm{MH} . \mathrm{MZ}$ was confirmed by coelution with non-radioactive $\left[{ }^{19} \mathrm{~F}\right] \mathrm{MH}$.MZ standard on analytical HPLC (Luna $5 \mu \mathrm{m}, \mathrm{C}-18$ column, acetonitrile/water/TFA 40/60/0.1 (v/v) - retention time $9.5 \mathrm{~min})$. The radiochemical purity of $\left[{ }^{18} \mathrm{~F}\right] \mathrm{MH} . \mathrm{MZ}$ was $>97 \%$ and molar activity was $22 \mathrm{GBq} / \mu \mathrm{mol}$. The resulting ethanol tracer solutions were diluted to the necessary volume in $0.1 \mathrm{M}$ sterile phosphate buffer.

\section{Dopamine $\mathrm{D}_{\mathbf{2}}$ Receptor Occupancy}

Five groups of female rats first received s.c. injections of $5 \%$ DMSO/saline vehicle $(n=16)$ or CNO [0.5 $(n=8), 2(n=6)$, $5(n=6)$ or $8(n=6) \mathrm{mg} / \mathrm{kg}]$ in $5 \% \mathrm{DMSO} /$ saline followed $20 \mathrm{~min}$ later by an i.v. injection of approximately $10 \mathrm{MBq}\left[{ }^{18} \mathrm{~F}\right]$ fallypride. The rats were anesthetized $40 \mathrm{~min}$ later with isoflurane (2$2.5 \%$ in oxygen) and placed in a homemade $2 \times 2$ rat insert in the aperture of a Siemens HRRT (High Resolution Research Tomograph) scanner (Keller et al., 2016) for a 45-min dynamic emission scan followed by a point source transmission scan (Tantawy et al., 2009, 2011). Scatter and attenuation corrections were performed, and the reconstructed PET image data were first 
cropped manually to a head-only image in PMOD v3.7, followed by motion correction with the PFUSEIT tool and summation for the purposes of registration. The images were corrected for body weight and injected dose using in-house code in MATLAB R2013a. The automatic co-registration with a tracer-specific PET template as target was executed in FSL 5.0.11 with the flirt command using the normalized correlation cost function with 12 degrees of freedom. A modified Logan reference tissue model with the cerebellum as reference region was used to calculate the binding potential $\left(\mathrm{BP}_{\mathrm{ND}}\right)$ in volumes of interest (VOIs) of bilateral dorsal or ventral striatum, as well as prefrontal cortex (Tantawy et al., 2009). Percent occupancy was calculated as the percent of the $\mathrm{BP}_{\mathrm{ND}}$ or specific binding ratio at a given dose of $\mathrm{CNO}$ in relation to vehicle administration.

\section{Serotonin 5-HT $2 A$ Receptor Occupancy}

Five groups of male ( $\mathrm{m}$, round) and female ( $\mathrm{f}$, triangle) rats first received s.c. injections of $5 \% \mathrm{DMSO} /$ saline vehicle $(n=7,4 \mathrm{~m} / 3 \mathrm{f})$ or CNO $(0.5(n=8,5 \mathrm{~m} / 3 \mathrm{f}), 2(n=8,6 \mathrm{~m} / 2 \mathrm{f}), 5(n=7,4 \mathrm{~m} / 3 \mathrm{f})$ or $8(n=5,5 \mathrm{~m}) \mathrm{mg} / \mathrm{kg})$ in $5 \% \mathrm{DMSO} / \mathrm{saline}$ followed $20 \mathrm{~min}$ later by an i.v. injection of $200 \mu \mathrm{L}\left[{ }^{18} \mathrm{~F}\right] \mathrm{MH} . \mathrm{MZ}$, approximately $10 \mathrm{MBq}$ at the time of first injection. $\left[{ }^{18} \mathrm{~F}\right] \mathrm{MH} . \mathrm{MZ}$-injected rats were killed by decapitation at $60 \mathrm{~min}$ of tracer circulation, and the extracted brain was dissected into weighed frontal cortex and cerebellum samples. The concentration of tracer was measured in a Packard Cobra gamma counter, calculated per gram of tissue, and reported as specific binding ratio ((frontal cortex cerebellum)/cerebellum). Percent occupancy was calculated as the percent of the $\mathrm{BP}_{\mathrm{ND}}$ or specific binding ratio at a given dose of $\mathrm{CNO}$ in relation to vehicle administration.

\section{Glutamate Levels}

Female rats (not the same rats as above) were anesthetized with isoflurane in oxygen, with induction at $3 \%$ and maintenance at $1.25-2.0 \%$ isoflurane during scans. All rats were scanned in the prefrontal cortex (30 min after) and in the right dorsal striatum (60 min after) after receiving s.c. injections of $5 \%$ $\mathrm{DMSO} /$ saline vehicle $(n=11 / 12)$ or CNO $(0.5(n=4), 2(n=8)$, or $5(n=4) \mathrm{mg} / \mathrm{kg})$ in $5 \% \mathrm{DMSO} / \mathrm{saline}$. Rats were scanned at baseline and after treatment (excepting four of the $2 \mathrm{mg} / \mathrm{kg}$ CNO treated animals, which were only scanned after treatment, and one scan that failed in prefrontal cortex). Structural images were obtained with TurboRARE sequences. Local magnetic field homogeneity was adjusted in a $2 \times 3 \times 3 \mathrm{~mm} / 18 \mu \mathrm{L}$ VOI in the prefrontal cortex and in a $3 \times 3 \times 3 \mathrm{~mm} / 27 \mu \mathrm{L}$ VOI in the right dorsal striatum using FASTMAP. The MRS/1HNMR spectrum was obtained using a STEAM (Stimulated Echo Acquisition Mode) sequence (TE: 3 ms, TR: 4000 ms, 400 ave, 4096 data points) with outer volume and VAPOR water suppression. All spectroscopy scans were performed on a Bruker BioSpec 94/30 USR MRI system (9.4 T, $30 \mathrm{~cm}$ bore, Bruker, Ettlingen, Germany) using a quadrature $86 \mathrm{~mm}$ rat body volume transmitter coil and 4 channel phase array receiver coil (Bruker, Ettlingen, Germany) with Paravision 5.3 software. MRS data was quantified with LCModel (Provencher, 1993) using simulated baseline and macro-molecule baseline.

\section{Statistics}

All data are expressed as mean \pm SD as calculated in Graphpad Prism v7.03. Significance of receptor occupancy changes was calculated with a one-way ANOVA with Dunnet's multiple corrections test; ANOVA summary is attached in the Supplementary Material. Significance in neurometabolite levels to MRS was calculated using a two-way ANOVA with Sidak's multiple corrections test. Significant levels are as follows: ${ }^{*} p<0.05,{ }^{* *} p<0.01$ and ${ }^{* * *} p<0.001$.

\section{RESULTS}

\section{Clozapine N-Oxide Induce Neuroreceptor Occupancy}

$\left[{ }^{18} \mathrm{~F}\right]$ Fallypride, which binds with high affinity $\left(K_{D}: 0.03 \mathrm{nM}\right)$ to dopamine $\mathrm{D}_{2 / 3}$ receptors in vitro (Mukherjee et al., 1995), is extensively used to measure dopamine or drug occupancy in dopamine $\mathrm{D}_{2 / 3}$ receptor rich regions of the living brain. After vehicle treatment, $\left[{ }^{18} \mathrm{~F}\right]$ fallypride $\mathrm{BP}_{\mathrm{ND}}$ was $0.72 \pm 0.18$ in the prefrontal cortex, $4.83 \pm 0.91$ in the dorsal striatum and $3.11 \pm 0.65$ in the ventral striatum (Figure 1). Pretreatment with $0.5 \mathrm{mg} / \mathrm{kg}$ CNO did not change the $\left[{ }^{18} \mathrm{~F}\right]$ fallypride $\mathrm{BP}_{\mathrm{ND}}$ in any region, but $2 \mathrm{mg} / \mathrm{kg}$ reduced $\mathrm{BP}_{\mathrm{ND}}$ by $36 \%$ in the prefrontal cortex $\left(\mathrm{BP}_{\mathrm{ND}}\right.$ at $2 \mathrm{mg} / \mathrm{kg} \mathrm{CNO}: 0.46 \pm 0.14$, Figures 1B,C). The effects of CNO $2 \mathrm{mg} / \mathrm{kg}$ in the prefrontal cortex were not evident at 5 and $8 \mathrm{mg} / \mathrm{kg}$ CNO. $5 \mathrm{mg} / \mathrm{kg}$ did not significantly affect the $\mathrm{BP}_{\mathrm{ND}}$ in any region, whereas $8 \mathrm{mg} / \mathrm{kg} \mathrm{CNO}$ reduced $\left[{ }^{18} \mathrm{~F}\right]$ fallypride $\mathrm{BP}_{\mathrm{ND}}$ by $34 \%$ in the dorsal and by $26 \%$ in ventral striatum $\left(\mathrm{BP}_{\mathrm{ND}}\right.$ at $8 \mathrm{mg} / \mathrm{kg} \mathrm{CNO}: 3.19 \pm 0.57$, Figures 1D,E and $2.29 \pm 0.25$, respectively, Figures $\mathbf{1 F}, \mathbf{G})$. There was a significant difference of $\mathrm{BP}_{\mathrm{ND}}$ between $\mathrm{CNO}$ treatments in the prefrontal cortex and dorsal striatum as calculated with an ordinary one-way ANOVA (Supplementary Tables 1-3). Furthermore, pretreatment with $0.5 \mathrm{mg} / \mathrm{kg} \mathrm{CNO}$ did not significantly change the specific binding ratio of $\left[{ }^{18} \mathrm{~F}\right] \mathrm{MH} . \mathrm{MZ}$ (a serotonin $5 \mathrm{HT}_{2 A}$ receptor ligand), whereas pretreatment with 2, 5 and $8 \mathrm{mg} / \mathrm{kg}$ reduced the binding ratio by 15,9 , and $14 \%$, respectively (Figures 2A,B). There was a significant effect of treatment between groups using an ordinary one-way ANOVA (Supplementary Table 4), although post hoc Dunnett's test revealed that no single dose significantly altered the binding ratio relative to the vehicle group (Supplementary Table 4).

\section{Clozapine N-Oxide Reduces Striatal Glutamate Levels}

Baseline metabolite concentration of creatine + phosphocreatine $(\mathrm{Cr}+\mathrm{PCr})$, glutamine $(\mathrm{Gln})$, glutamate $(\mathrm{Glu}), N$-acetylaspartate $+N$-acetylaspartate glutamate (NAA $+\mathrm{NAAG})$ and total glutamine + glutamate (Gln + Glu) were quantified from the obtained MR spectrum (Figure 3C) in prefrontal cortex (Figure 3D) and dorsal striatum (Figure 3E), as reported in detail in the Supplementary Material (Supplementary Table 5): GABA and glucose could not be reliably quantified in all rats using this voxel size and scan sequence. A representative spectrum and voxel placement are presented in Figures 3A-C. There was 


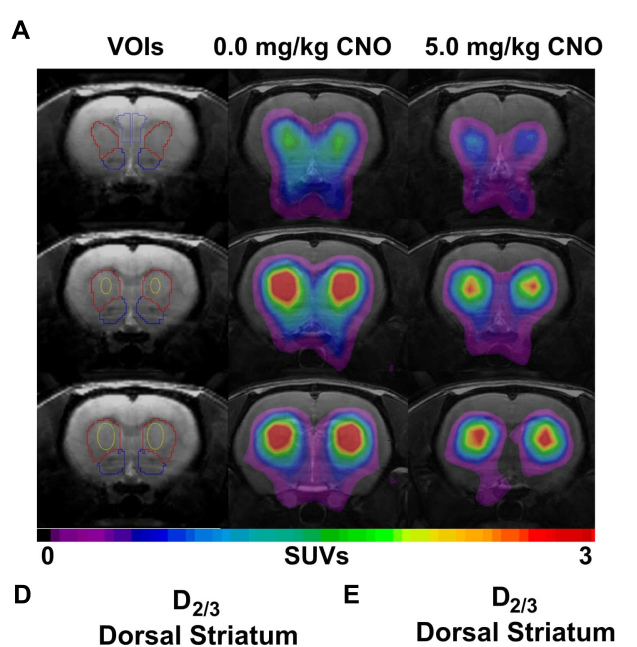

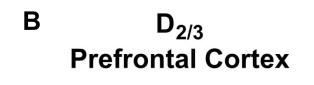

$$
\begin{array}{cc}
C & D_{2 / 3} \\
& \text { Prefrontal Cortex }
\end{array}
$$
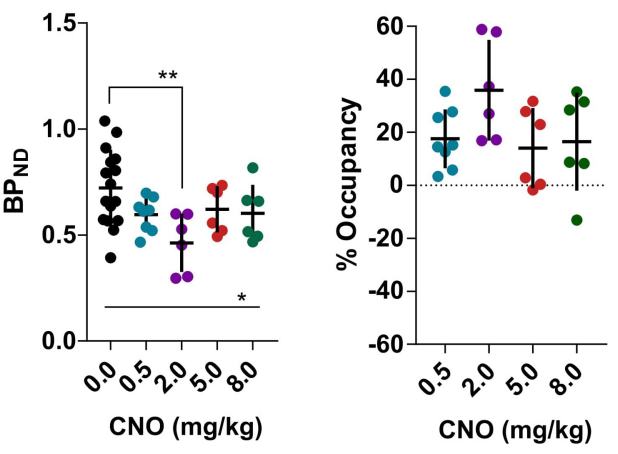

F

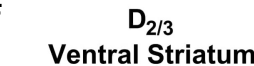

G $\quad \mathrm{D}_{2 / 3}$
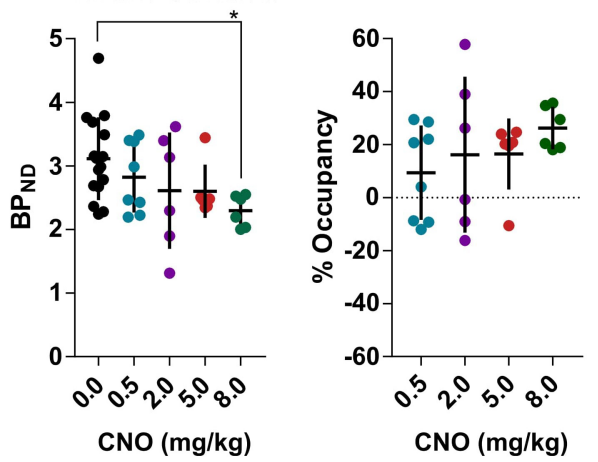

FIGURE 1 [ $\left.{ }^{18} \mathrm{~F}\right]$ Fallypride binding in the rat prefrontal cortex and striatal regions (A), $5 \mathrm{mg} / \mathrm{kg}$ Clozapine N-oxide (CNO) induced a noticeable decline in receptor availability in the same rat (A). CNO induced occupancy on a group level at the dopamine $D_{2 / 3}$ receptors in the prefrontal cortex (B,C) as well as dorsal (D,E) and ventral $\mathbf{( F , G ) ~ s t r i a t u m . ~ H o r i z o n t a l ~ l i n e s ~ a n d ~ * r e p r e s e n t s ~ a ~ s i g n i f i c a n t ~ e f f e c t ~ o f ~ t r e a t m e n t s , ~ a s ~ m e a s u r e d ~ w i t h ~ a ~ o n e - w a y ~ A N O V A ~}\left({ }^{*} p<0.05,{ }^{*} p<0.01\right.$ and $* * * p<0.001)$.
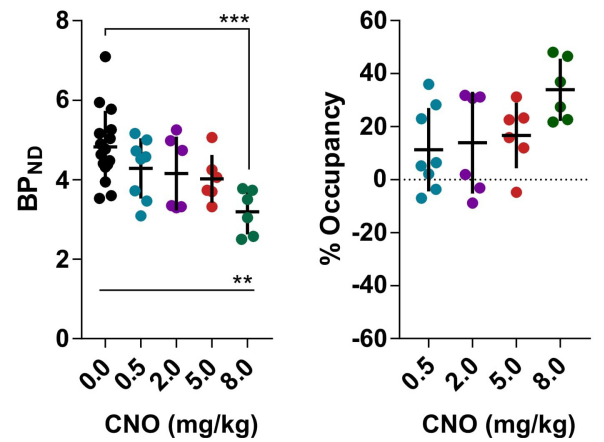

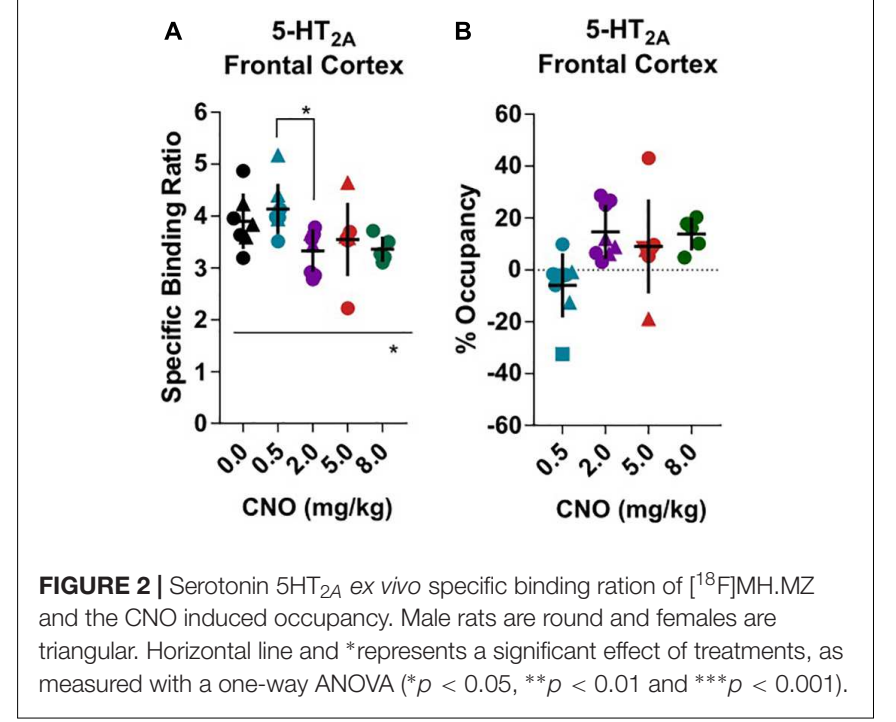

no effect of pretreatment with $0.5 \mathrm{mg} / \mathrm{kg} \mathrm{CNO}$ in comparison to vehicle in either the prefrontal cortex or dorsal striatum. However, pretreatment with $2 \mathrm{mg} / \mathrm{kg}$ CNO induced a significant decrease in $\mathrm{Cr}+\mathrm{PCr}(-11 \%, 5.32 \pm 0.19 \mathrm{mM}, p=0.0032)$ and an increase in NAA+NAAG $(14 \%, 5.89 \pm 0.27 \mathrm{mM}$, $p=0.0095)$ concentrations in the prefrontal cortex. Furthermore, pretreatment with $2 \mathrm{mg} / \mathrm{kg}$ CNO also induced decreased glutamate $(-9 \%, 5.79 \pm 0.82 \mathrm{mM}, p=0.0251)$ and total glutamate + glutamine $(-7 \%, 8.34 \pm 0.84 \mathrm{mM}, p=0.0080)$ concentrations in the dorsal striatum (Statistics are reported in Supplementary Tables 7, 8).

\section{DISCUSSION}

The results confirm our hypothesis that CNO induces occupancy at dopamine $\mathrm{D}_{2 / 3}$ and serotonin $5-\mathrm{HT}_{2 A}$ receptors in Long-Evans rats, albeit without providing direct insight into the basis of this occupancy. It has been reported that CNO converts to CLZ in vivo, producing a peak CLZ plasma concentration between 10 and $30 \mathrm{~min}$ (Meier, 1975; MacLaren et al., 2016). Administration of CNO at a dose of $5 \mathrm{mg} / \mathrm{kg}$ generated $0.28 \mu \mathrm{M}$ (about $92 \mathrm{ng} / \mathrm{mL}$ ) CLZ in the plasma (MacLaren et al., 2016; Gomez et al., 2017) at $30 \mathrm{~min}$ after treatment. Baldessarini et al. found a similar CLZ concentration $1 \mathrm{~h}$ after an acute dose of $10 \mathrm{mg} / \mathrm{kg}$ CLZ i.p (Baldessarini et al., 1993). There is a two-phase correlation 
A

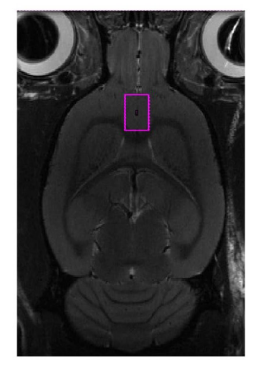

B

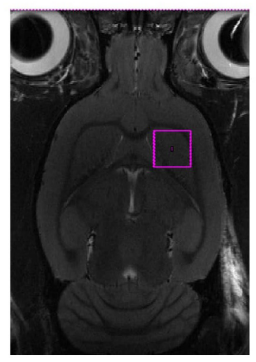

D

Prefrontal Cortex
C

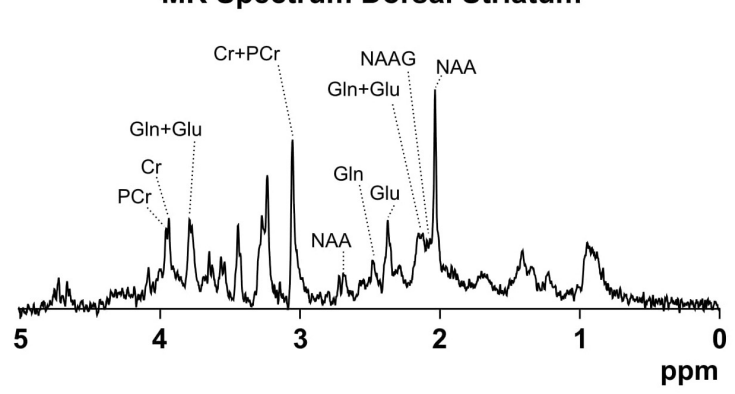

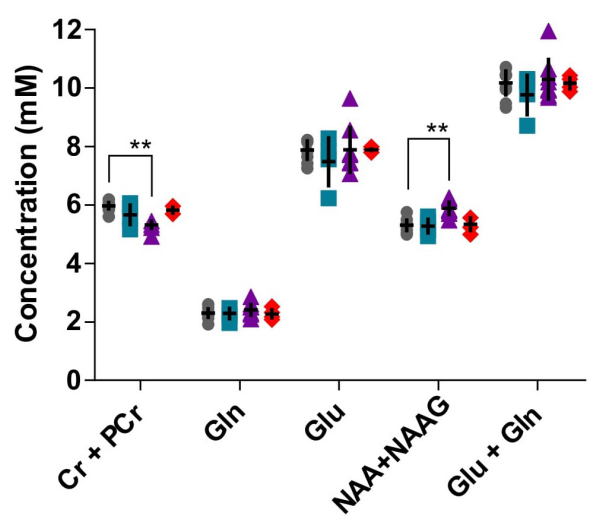

E

\section{Dorsal Striatum}

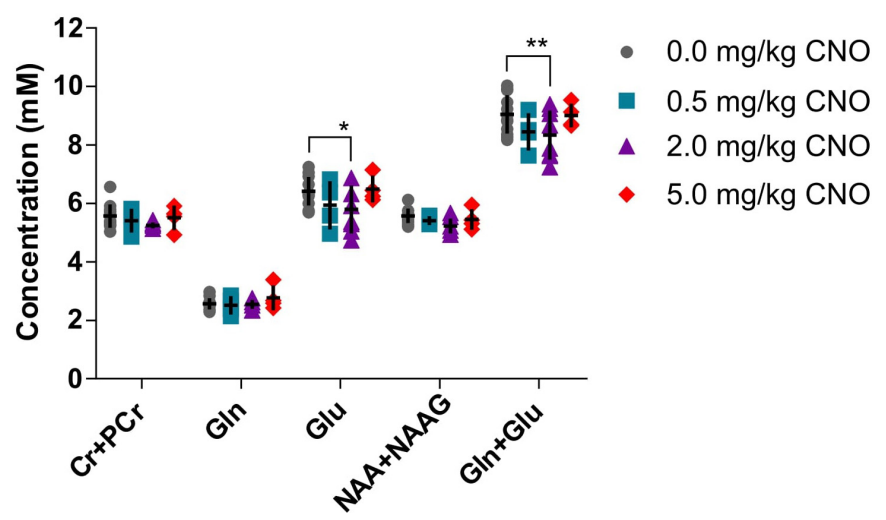

FIGURE 3 | Neurometabolite concentrations as measured in vivo using MR spectroscopy. Cubic voxels $18 \mu \mathrm{L}$ in the prefrontal cortex (A) and $27 \mu \mathrm{L}$ dorsal striatum (B). A sample spectrum (C) from the voxel in the dorsal striatum and metabolite concentrations in the voxels following pretreatments with different doses of CNO in the prefrontal cortex (D) and in the dorsal striatum (E). ${ }^{*} p<0.05, * * p<0.01$ and ${ }^{* * *} p<0.001$ two-way ANOVA with Sidak's multiple corrects test.

between plasma CLZ levels and the occupancy at dopamine $\mathrm{D}_{2 / 3}$ receptors (Mukherjee et al., 2001; Olsen et al., 2008); the plateau for the first phase occurred with doses in the range of 0.1 to $40 \mathrm{mg} / \mathrm{kg}$ CLZ i.p., These doses provoked a striatal occupancy of $20-50 \%$, which is often considered as the therapeutic window for CLZ for the treatment of schizophrenia. In a rat $\left[{ }^{18} \mathrm{~F}\right]$ fallypride PET study, Mukherjee et al. (2001) found a 30\% occupancy level at $2 \mathrm{~h}$ after administration of $10 \mathrm{mg} / \mathrm{kg} \mathrm{CLZ}$. Although the exact occupancy by CLZ is dependent on the time of pretreatment and PET acquisition (Olsen et al., 2008), there is general agreement with our findings for CNO, which induced 26-39\% dopamine $\mathrm{D}_{2 / 3}$ occupancy in the striatal regions at $1 \mathrm{~h}$ after injection of $8 \mathrm{mg} / \mathrm{kg} \mathrm{CNO}$. CLZ is known to induce dopamine release in the medial prefrontal cortex (Rowley et al., 2000) to a higher extent than in the dorsal striatum (Karoum and Egan, 1992). Therefore, it is likely that the inverted $\mathrm{u}$-shape of CLZ-induced occupancy in the prefrontal cortex arises from dopamine release.

As mentioned above, the affinity of $\mathrm{CNO}$ for $5-\mathrm{HT}_{2 A}$ receptors (ID 50 1-2 $\mathrm{mg} / \mathrm{kg}$ ) exceeds that for dopamine $\mathrm{D}_{2 / 3}$ receptors (ID $5020 \mathrm{mg} / \mathrm{kg}$ ) (Schotte et al., 1993; Zhang and Bymaster, 1999). Present results support this by showing cortical $5-\mathrm{HT}_{2 A}$ receptor occupancy at low doses (Figures 2A,B) compared with $\mathrm{D}_{2 / 3}$ in the striatal regions. Knauer et al. found a CLZ dose-dependent occupancy of $5-\mathrm{HT}_{2 A}$ receptors, with a plasma concentration of $92 \mathrm{ng} / \mathrm{mL}$ giving $50-75 \%$ occupancy
(Knauer et al., 2008). However, several questions arise from these $\left[{ }^{18} \mathrm{~F}\right] \mathrm{MH} . \mathrm{MZ}$ experiments. First, CLZ occupancy of $\left[{ }^{18} \mathrm{~F}\right] \mathrm{MH} . \mathrm{MZ}$ binding sites has not hitherto been established, so there is no direct literature we can compare to. Second, we do not know if CLZ and $\left[{ }^{18} \mathrm{~F}\right] \mathrm{MH} . \mathrm{MZ}$ share the same binding site on the $5 \mathrm{HT}_{2 A}$ receptors. We choose to include this experimental data because it provides some explanation as to why we detected effects on neurochemicals and $\mathrm{D}_{2 / 3}$ receptor occupancy at a CNO dose of $2 \mathrm{mg} / \mathrm{kg}$. As previously noted, CLZ also bind to other neuroreceptors with higher affinity than toward dopamine $\mathrm{D}_{2}$ receptors. For the present, we can only assume that occupancy of these receptors will likely exceed that of the $\mathrm{D}_{2}$ receptors.

In vivo evidence of acute CLZ effects on neurometabolite levels is sparsely documented, although we know that chronic clozapine treatment does effect levels of glutamate, glutamine, creatine, NAA+NAAG and other metabolites (McLoughlin et al., 2009). Likewise, CLZ is without effect on the activity of nGCP II, the enzyme that catabolizes NAAG to glutamate (Flores and Coyle, 2003), or creatine kinase, the enzyme that catabolizes creatine to phosphocreatine (Assis et al., 2007; Scaini et al., 2013). The effects of CLZ on glutamate levels and glutamate signaling are particularly ambiguous. Some authors have reported that acute CLZ inhibited corticostriatal signaling and lowered glutamate release in PFC terminals (Lidsky et al., 1993; Yang and Wang, 2005), while others have reported increased glutamate release in 
the PFC (Tanahashi et al., 2012). Interestingly, selective $5-\mathrm{HT}_{2 \mathrm{~A}}$ antagonists decrease glutamate concentrations in the dorsal striatum (Ansah et al., 2011), likely by blockade of the $5-\mathrm{HT}_{2 \mathrm{~A}}$ receptors, which are mainly located on the somatic and dendritic region of corticostriatal pyramidal neurons (Miner et al., 2003). We suppose that $5-\mathrm{HT}_{2 A}$ inhibition of glutamate release in dorsal striatum could precede the glutamate release potentiated by other means, as the inhibitory effect on glutamate was evident with a CNO dose $(2 \mathrm{mg} / \mathrm{kg})$ lower than that causing discernible occupancy at $\mathrm{D}_{2 / 3}$ receptors $(5 \mathrm{mg} / \mathrm{kg})$. Such a bidirectional activation and inhibition could explain the effects that we and others observe, but further studies are needed to elucidate the neurochemical basis of the observed effects of $\mathrm{CNO}$ and to confirm that these effects are indeed precipitated by conversion of CNO to CLZ in the living rodent. However, these data confirm that $\mathrm{CNO}$ is not a neurochemically inert drug and call for caution in the attribution of effects of CNO in the context of chemogenetic (DREADD) ligand studies.

\section{DATA AVAILABILITY}

Raw data can be obtained by contacting the corresponding author.

\section{AUTHOR CONTRIBUTIONS}

SB carried out most animal experiments, analyzed the data and assisted in writing the manuscript. AC-S assisted in the animal experiments, data analysis and writing of the manuscript. DL automated PET image co-registration, motion correction and kinetic modeling. VS synthesized $\left[{ }^{18} \mathrm{~F}\right] \mathrm{MH} . \mathrm{MZ}$ and assisted in PET experiments. IT assisted in PET data analysis. MX assisted

\section{REFERENCES}

Agulhon, C., Boyt, K. M., Xie, A. X., Friocourt, F., Roth, B. L., and McCarthy, K. D. (2013). Modulation of the autonomic nervous system and behaviour by acute glial cell Gq protein-coupled receptor activation in vivo. J. Physiol. 591, 5599-5609. doi: 10.1113/jphysiol.2013.261289

Ansah, T. A., Ferguson, M. C., and Nayyar, T. (2011). The 5-HT(2A) receptor antagonist M100907 produces antiparkinsonian effects and decreases striatal glutamate. Front. Syst. Neurosci. 5:48. doi: 10.3389/fnsys.2011. 00048

Armbruster, B. N., Li, X., Pausch, M. H., Herlitze, S., and Roth, B. L. (2007). Evolving the lock to fit the key to create a family of $G$ protein-coupled receptors potently activated by an inert ligand. Proc. Natl. Acad. Sci. U.S.A. 104, 5163-5168. doi: 10.1073/pnas.0700293104

Arun, P., Madhavarao, C. N., Moffett, J. R., and Namboodiri, A. M. A. (2008). Antipsychotic drugs increase $\mathrm{N}$-acetylaspartate and $\mathrm{N}$-acetylaspartylglutamate in SH-SY5Y human neuroblastoma cells. J. Neurochem. 106, 1669-1680. doi: 10.1111/j.1471-4159.2008.05524.x

Assis, L. C., Scaini, G., Di-Pietro, P. B., Castro, A. A., Comim, C. M., Streck, E. L., et al. (2007). Effect of antipsychotics on creatine kinase activity in rat brain. Basic Clin. Pharmacol. Toxicol. 101, 315-319. doi: 10.1111/j.1742-7843.2007. 00128.x

Baldessarini, R. J., Centorrino, F., Flood, J. G., Volpicelli, S. A., Huston-Lyons, D., and Cohen, B. M. (1993). Tissue concentrations of clozapine and its metabolites in the rat. Neuropsychopharmacology 9, 117-124. doi: 10.1038/npp.1993.50

Baslow, M. H., Cain, C. K., Sears, R., Wilson, D. A., Bachman, A., Gerum, S., et al. (2016). Stimulation-induced transient changes in neuronal activity, blood in the animal experiments. EL established the synthesis and novel HPLC method of $\left[{ }^{18} \mathrm{~F}\right]$ fallypride, and assisted in PET experiments and data analysis. FE synthesized $\left[{ }^{18} \mathrm{~F}\right]$ fallypride and assisted in PET experiments. HL established the MRS sequence, assisted in analyzing the MRS spectra, and edited the manuscript. MMH planned the radiochemical and PET experiments, discussed the data, and edited the manuscript. MP planned the whole study, established the PET imaging protocol, carried out experiments, analyzed PET and MRS data, and wrote the manuscript. All authors have read and approved the manuscript.

\section{FUNDING}

The authors are thankful for contributions from the Lundbeck Foundation (Grant Nos. 2015-1591 and 2015-1589), the Independent Research Fund Denmark (Grant No. 5053-00036B) and Denmarks Innovation Fund (Grant No. 4108-00004B).

\section{ACKNOWLEDGMENTS}

We acknowledge Joe Lorenz for proofreading, Louise Nielsen for laboratory assistance, and manuscript editing by Inglewood Biomedical Editing.

\section{SUPPLEMENTARY MATERIAL}

The Supplementary Material for this article can be found online at: https://www.frontiersin.org/articles/10.3389/fnins. 2019.00187/full\#supplementary-material

flow and N-acetylaspartate content in rat prefrontal cortex: a chemogenetic fMRS-BOLD study. NMR Biomed. 29, 1678-1687. doi: 10.1002/nbm. 3629

Bymaster, F. P., Calligaro, D. O., Falcone, J. F., Marsh, R. D., Moore, N. A., Tye, N. C., et al. (1996). Radioreceptor binding profile of the atypical antipsychotic olanzapine. Neuropsychopharmacology 14, 87-96. doi: 10.1016/0893-133X(94) 00129-N

Chen, X., Choo, H., Huang, X. P., Yang, X., Stone, O., Roth, B. L., et al. (2015). The first structure-activity relationship studies for designer receptors exclusively activated by designer drugs. ACS Chem. Neurosci. 6, 476-484. doi: 10.1021/ $\operatorname{cn} 500325 \mathrm{v}$

Flores, C., and Coyle, J. T. (2003). Regulation of glutamate carboxypeptidase II function in corticolimbic regions of rat brain by phencyclidine, haloperidol, and clozapine. Neuropsychopharmacology 28, 1227-1234. doi: 10.1038/sj.npp. 1300129

Gomez, J. L., Bonaventura, J., Lesniak, W., Mathews, W. B., Sysa-shah, P., Rodriguez, L. A., et al. (2017). Chemogenetics revealed: dreadd occupancy and activation via converted clozapine. Science 357, 503-507. doi: 10.1126/science. aan 2475

Herth, M. M., Debus, F., Piel, M., Palner, M., Knudsen, G. M., Lüddens, H., et al. (2008). Total synthesis and evaluation of [18F]MHMZ. Bioorg. Med. Chem. Lett. 18, 1515-1519. doi: 10.1016/j.bmcl.2007.12.054

Jann, M. W., Grimsley, S. R., Gray, E. C., and Chang, W. H. (1993). Pharmacokinetics and pharmacodynamics of clozapine. Clin. Pharmacokinet. 24, 161-176. doi: 10.2165/00003088-199324020-00005

Karoum, F., and Egan, M. (1992). Dopamine release and metabolism in the rat frontal cortex, nucleus accumbens, and striatum: a comparison of acute 
clozapine and haloperidol. Br. J. Pharmacol. 105, 703-707. doi: 10.1111/j.14765381.1992.tb09042.x

Keller, S. H., L'Estrade, E. N., Dall, B., Palner, M., and Herth, M. (2016). "Quantification accuracy of a new HRRT high throughput rat hotel using transmission-based attenuation correction: a phantom study," in Proceedings of the 2016 IEEE Nuclear Science Symposium, Medical Imaging Conference and Room-Temperature Semiconductor Detector Workshop (NSS/MIC/RTSD), (Piscataway, NJ: IEEE), 1-3. doi: 10.1109/NSSMIC.2016.8069467

Knauer, C. S., Campbell, J. E., Galvan, B., Bowman, C., Osgood, S., Buist, S., et al. (2008). Validation of a rat in vivo [3H]M100907 binding assay to determine a translatable measure of 5-HT2A receptor occupancy. Eur. J. Pharmacol. 591, 136-141. doi: 10.1016/j.ejphar.2008.06.063

Krivoy, A., Hochman, E., Sendt, K.-V., Hollander, S., Vilner, Y., Selakovic, M., et al. (2017). Association between serum levels of glutamate and neurotrophic factors and response to clozapine treatment. Schizophr. Res. 192, 226-231. doi: 10.1016/j.schres.2017.05.040

Lidsky, T. I., Yablonsky-Alter, E., Zuck, L., and Banerjee, S. P. (1993). Antiglutamatergic effects of clozapine. Neurosci. Lett. 163, 155-158. doi: 10.1016/ 0304-3940(93)90370-Z

Lin, G., McKay, G., and Midha, K. K. (1996). Characterization of metabolites of clozapine $\mathrm{N}$-oxide in the rat by micro-column high performance liquid chromatography/mass spectrometry with electrospray interface. J. Pharm. Biomed. Anal. 14, 1561-1577. doi: 10.1016/0731-7085(96)01738-4

MacLaren, D. A. A., Browne, R. W., Shaw, J. K., Krishnan Radhakrishnan, S., Khare, P., Espana, R. A., et al. (2016). Clozapine N-Oxide administration produces behavioral effects in long-evans rats: implications for designing DREADD experiments. eNeuro 3:ENEURO.219-ENEURO.216. doi: 10.1523/ ENEURO.0219-16.2016

McLoughlin, G. A., Ma, D., Tsang, T. M., Jones, D. N. C., Cilia, J., Hill, M. D., et al. (2009). Analyzing the effects of psychotropic drugs on metabolite profiles in rat brain using $1 \mathrm{H}$ NMR spectroscopy. J. Proteome Res. 8, 1943-1952. doi: $10.1021 /$ pr800892u

Meier, J. (1975). Bioanalytical assay of clozapine and its N-oxide metabolite and the determination of their blood levels in the dog. Br. J. Pharmacol. 53:440.

Miner, L. A. H., Backstrom, J. R., Sanders-Bush, E., and Sesack, S. R. (2003). Ultrastructural localization of serotonin $2 \mathrm{~A}$ receptors in the middle layers of the rat prelimbic prefrontal cortex. Neuroscience 116, 107-117. doi: 10.1016/S0306$4522(02) 00580-8$

Mukherjee, J., Christian, B. T., Narayanan, T. K., Shi, B., and Mantil, J. (2001). Evaluation of dopamine D-2 receptor occupancy by clozapine, risperidone, and haloperidol in vivo in the rodent and nonhuman primate brain using 18 F-fallypride. Neuropsychopharmacology 25, 476-488. doi: 10.1016/S0893$133 \mathrm{X}(01) 00251-2$

Mukherjee, J., Yang, Z. Y., Das, M. K., and Brown, T. (1995). Fluorinated benzamide neuroleptics-III. Development of (S)-N-[(1-allyl-2-pyrrolidinyl) methyl]-5-(3-[18F]fluoropropyl)-2, 3-dimethoxybenzamide as an improved dopamine D-2 receptor tracer. Nucl. Med. Biol. 22, 283-296. doi: 10.1016/09698051(94)00117-3

Olsen, C. K., Brennum, L. T., and Kreilgaard, M. (2008). Using pharmacokineticpharmacodynamic modelling as a tool for prediction of therapeutic effective plasma levels of antipsychotics. Eur. J. Pharmacol. 584, 318-327. doi: 10.1016/j. ejphar.2008.02.005

Piel, M., Schmitt, U., Bausbacher, N., Buchholz, H.-G., Gründer, G., Hiemke, C., et al. (2014). Evaluation of P-glycoprotein (abcbla/b) modulation of [18F] fallypride in MicroPET imaging studies. Neuropharmacology 84, 152-158. doi: 10.1016/j.neuropharm.2013.04.062
Provencher, S. W. (1993). Estimation of metabolite concentrations from localized in vivo proton NMR spectra. Magn. Reson. Med. 30, 672-679. doi: 10.1002/ mrm.1910300604

Rowley, H. L., Needham, P. L., Kilpatrick, I. C., and Heal, D. J. (2000). A comparison of the acute effects of zotepine and other antipsychotics on rat cortical dopamine release, in vivo. Naunyn. Schmiedebergs. Arch. Pharmacol. 361, 187-192. doi: 10.1007/s002109900170

Scaini, G., Rochi, N., Morais, M. O. S., Maggi, D. D., De-Nês, B. T., Quevedo, J., et al. (2013). In vitro effect of antipsychotics on brain energy metabolism parameters in the brain of rats. Acta Neuropsychiatr. 25, 18-26. doi: 10.1111/ j.1601-5215.2012.00650.x

Schotte, A., Janssen, P. F., Megens, A. A., and Leysen, J. E. (1993). Occupancy of central neurotransmitter receptors by risperidone, clozapine and haloperidol, measured ex vivo by quantitative autoradiography. Brain Res. 631, 191-202. doi: 10.1016/0006-8993(93)91535-Z

Tanahashi, S., Yamamura, S., Nakagawa, M., Motomura, E., and Okada, M. (2012). Clozapine, but not haloperidol, enhances glial $\mathrm{d}$-serine and L-glutamate release in rat frontal cortex and primary cultured astrocytes. Br. J. Pharmacol. 165, 1543-1555. doi: 10.1111/j.1476-5381.2011.01638.x

Tantawy, M. N., Jones, C. K., Baldwin, R. M., Ansari, M. S., Conn, P. J., Kessler, R. M., et al. (2009). [18F]Fallypride dopamine D2 receptor studies using delayed microPET scans and a modified Logan plot. Nucl. Med. Biol. 36, 931-940. doi: 10.1016/j.nucmedbio.2009.06.007

Tantawy, M. N., Peterson, T. E., Jones, C. K., Johnson, K., Rook, J. M., Conn, P. J., et al. (2011). Impact of isoflurane anesthesia on D2 receptor occupancy by [18F] fallypride measured by microPET with a modified Logan plot. Synapse 65, 1173-1180. doi: 10.1002/syn.20955

Urban, D. J., Zhu, H., Marcinkiewcz, C. A., Michaelides, M., Oshibuchi, H., Rhea, D., et al. (2015). Elucidation of the behavioral program and neuronal network encoded by dorsal raphe serotonergic neurons. Neuropsychopharmacology 41, 1404-1415. doi: 10.1038/npp. 2015.293

Yamamoto, B. K., and Cooperman, M. A. (1994). Differential effects of chronic antipsychotic drug treatment on extracellular glutamate and dopamine concentrations. J. Neurosci. 14, 4159-4166. doi: 10.1523/JNEUROSCI.14-0704159.1994

Yang, T.-T., and Wang, S.-J. (2005). Effects of haloperidol and clozapine on glutamate release from nerve terminals isolated from rat prefrontal cortex. Synapse 56, 12-20. doi: 10.1002/syn.20123

Zhang, W., and Bymaster, F. P. (1999). The in vivo effects of olanzapine and other antipsychotic agents on receptor occupancy and antagonism of dopamine D 1, D 2, D 3, 5HT 2A and muscarinic receptors. Psychopharmacology 141, 267-278. doi: $10.1007 /$ s002130050834

Conflict of Interest Statement: The authors declare that the research was conducted in the absence of any commercial or financial relationships that could be construed as a potential conflict of interest.

Copyright (๑ 2019 Bærentzen, Casado-Sainz, Lange, Shalgunov, Tejada, Xiong, L'Estrade, Edgar, Lee, Herth and Palner. This is an open-access article distributed under the terms of the Creative Commons Attribution License (CC BY). The use, distribution or reproduction in other forums is permitted, provided the original author(s) and the copyright owner(s) are credited and that the original publication in this journal is cited, in accordance with accepted academic practice. No use, distribution or reproduction is permitted which does not comply with these terms. 